\title{
SCIENTIFIC WORK OF THE ZIEGLER POLAR EXPEDITION.
}

\section{WiLI,IAM J. PETERS. ${ }^{1}$}

The Ziegler Polar Expedition, which left Norway, July 10, 1903, was not intended to be a scientific expedition. Only such scientific work was contemplated as would further the ends of the expedition and also such as could be done without detriment or delay.

Meteorological observations were begun immediately after leaving Norway and continued without interruption to the date of the return, July 28, 5905. These observations were made and recorded according to the methods of the United States Weather Bureau.

Magnetic observations, consisting of declination, horizontal intensity, and dip, were made from October I, I903, to June 29, 1904, at Teplitz Bay, according to a program arranged by Dr. L. A. Bauer, with an outfit loaned by the United States Coast and Geodetic Survey. This embraced two-minute eye-readings of declination for twenty-four hours on Wednesdays, and for periods of consecutive four hours on every other day of the week. Horizontal intensity and dip were observed weekly. This program was carried out also at Alger Island for four weeks in July, 1905. Owing to stress of weather there are a few breaks in the continuity of the record. Some magnetic results were obtained on the ice in Barents Sea.

Astronomic observations, made with a Repsold circle, include observations for time, latitude, azimuth, and moon culminations at Teplitz Bay, and observations for time, azimuth, and latitude at Alger Island, during the summer of 1905 .

Tidal observations were made for three months at Teplitz Bay, and for four months at Cape Flora, in 1904. In 1905, another record of one month was made at Cape Flora.

The exploration and charting of Franz Josef Land were made in the summers of 1904 and 1905 with such satisfactory results that there is very little left to be done.

No attempt was made to collect or note anything of interest to natural history, but the relief expedition of 1905, under Mr. Champ, brought back a few live specimens.

1 Mr. Peters was the representative on the Expedition of the National Geographical Society of Washington, and was second in command. He is now engaged in the reduction and discussion of his observations to be published by the trustees of the Ziegler estate.-E,d. 